\title{
PARAMETRIC EFFECTS ON THE PERFORMANCE OF AN INDUSTRIAL COOLING TOWER
}

\author{
O.T. Bamimore ${ }^{1}$, S.O. Enibe ${ }^{1}$, Paul. A. Adedeji ${ }^{2,3, *}$
}

\begin{abstract}
Sensible and latent heat rejection from heat engines is of high necessity for system efficiency and continuous production. The cooling tower is one of the major heat-exchanging systems used for cooling industrial heat systems by intimately mixing hot water with cooling air. Optimal operating conditions and parameters of the system are highly essential for its effectiveness and efficiency. This study used the Poppe model to evaluate selected thermodynamic relations of a rectangular counter-flow industrial cooling tower of a steel rolling mill using the system's inlet and outlet data as initial conditions. The effect of increasing the water temperature on the air moisture content, Merkel number, and specific enthalpy was studied across the fills of the cooling tower. Air moisture content, Merkel number and specific enthalpy of the system increase with increasing water temperature. However, while other variables reach a stationary point at half the nodal segments, the specific enthalpy increases across the fills in the system. It was concluded that the use of nano particles with high heat removal rate could increase the efficiency of the system. Also, an increase in the quantity of the makeup water of a force draft system is recommended towards increasing the system efficiency.
\end{abstract}

\section{Keywords: Cooling Tower, Natural Draft, Parametric Modelling, Poppe Model}

\section{INTRODUCTION}

Many manufacturing systems are associated with a heat removal process. The waste heat is removed most often by circulating cooling water across the system [1-3]. An efficient removal of the waste heat from these systems significantly affects the performance and lifecycle of these systems [4]. Cooling towers are mostly used in these systems as heat-extracting systems and have found relevance in petrochemical industries, refrigeration and air conditioning systems, power plants, steel rolling mills and so on [5,6]. A typical cooling tower chamber is divided into fills and each fill receives the cooling fluid carrying sensible heat. The fills increase the surface area available for heat rejection from the thermodynamic system. The direction of movement of air in the cooling tower system is used to characterize it as either counter-flow or cross-flow. In cross-flow cooling towers, ambient air entering the system travels horizontally through the fills as the hot water moves downwards while for the counter flow, ambient air travels in opposite direction to the hot water movement [7,8]. Figure 1 shows a classification of cooling towers based on draft, airflow, construction, shape, and heat transfer. In this study, a rectangular mechanical draft cross flow industrial cooling tower of a typical steel rolling mill was considered.

Several mathematical models have been developed for analysis of the thermal behaviour of wet cooling tower. For example, heat and mass transfer process in wet cooling towers was first practically modelled by Merkel [9]. The Merkel model presents a simplified heat and mass equations of enthalpy difference. The model takes the Lewis factor as unity (1), which neglects the reduction in the mass flow rate of water consequential to evaporation [10]. Similar to Merkel model are the Poppe and $\varepsilon$ - number of transfer units ( $\varepsilon$-NTU) models. Kloppers and Kroger [11] investigated the differences between the Merkel, Poppe, and the $\varepsilon$-NTU models. Their findings concluded that the less accurate Merkel and $\varepsilon$-NTU approach fits best when outlet water temperature constitutes the only significant parameter to the cooling tower designer. However, these two models give lower values than the Poppe model when heat transfer rate is

This paper was recommended for publication in revised form by Regional editor Omid Mahian

${ }^{1}$ Department of Mechanical Engineering, University of Nigeria, Nsukka

${ }^{2}$ Department of Industrial and Production Engineering, University of Ibadan, Nigeria

${ }^{3}$ Department of Mechanical Engineering Science, University of Johannesburg, South Africa

Email address: pauladedeji2k5@gmail.com

ORCID id: 0000-0002-2212-0623

Manuscript Received 15 April 2019, Accepted 26 August 2019 
of interest. The effect of the Lewis number and heat transfer resistance in the air-water interface was also investigated by Khan and Zubair [12] where a detailed model was developed for a counterflow wet cooling tower. On the contrary, Prasad [13] developed a numerical model for cross-flow wet cooling towers. The model was applied to the packing of a multi-cell cross-flow cooling tower to estimate the variance of fill characteristics from their functional design values.

Also, for cross-flow cooling towers, Hajidavalloo et al. [14] applied the Merkel's model to predict the thermal performance of an existing cross-flow tower at varying wet bulb temperature. The authors compared the numerical results with the experimental results under varying operating conditions.

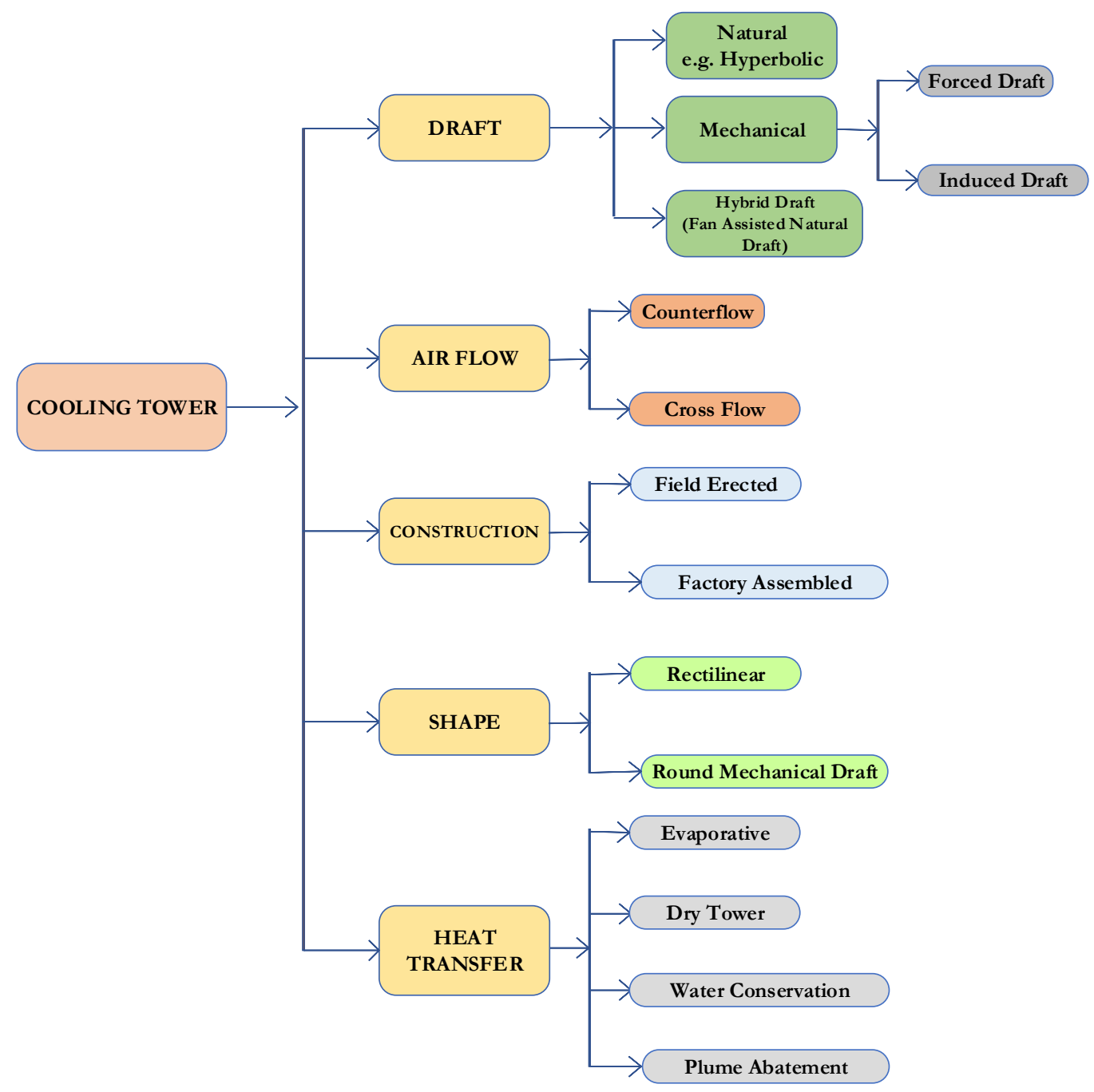

Figure 1. Categories of cooling tower

Several thermodynamic parameters affect both the physical structure and the efficiency of the cooling tower. Some of these include the water inlet and outlet temperatures, specific enthalpy, Merkel Number, variation of mass transfer across the system and so on. The wet bulb temperature also affects the tower efficiency and this varies inversely with the tower size [15]. Obtaining optimal design parameters predicates an efficient cooling tower. The range of the tower (difference between hot water temperature entering and the cold water exiting the tower) exhibits inverse variation with the size of the tower [16]. The variation in these parameters with temperature change across the system and the significance of this variation in sustaining efficiency and effectiveness of the system is of paramount importance. 
Asides from white-box models, black-box models have also demonstrated relevance in predictive and analytical models in energy systems [17-19] and cooling systems [20,21]. These models map inputs to output(s) without necessarily having a prior understanding of the system being modelled. They are data-driven models which operates intelligently by fitting data into a model but do not explicitly give details of their mode of operations. This influences their nomenclature as being a black-box [22]. Recent developments in cooling systems have demonstrated the efficiency of black-box models and their hybrids with evolutionary algorithms in predictive analysis and parameter optimization[23,24]. Significant among these studies is the work of Rashidi et al. [24]. The study developed a multiobjective optimization model, which optimizes the exergy efficiency, thermal efficiency, and specific work for regenerative Clausius and organic Rankine cycles with two integrated feedwater heaters. The study uses three multilayer artificial neural network (MLP-ANN) model and artificial bee colony technique for function optimization. Also, another study by the author[25] proceeds using ANN and particle swarm optimization (PSO) to minimize entropy generation of a stretchable rotating disc relevant in thermal system design. Many other studies have used both evolutionary algorithm and black box models in cooling tower analysis [20,21,26-28]. These studies, however, do not undermine the significance of numerical modelling of the cooling tower system as most data for the black box models were obtained either from historical records, experimental procedures, or numerical simulations.

The cooling tower efficiency during operation and within its useful life is affected by several thermodynamic variants [29]. These variants not only culminate to affect the efficiency of the cooling tower but also has impact on the useful life of the system. The Poppe's model is popular in its use in the assessment of large-scale power plants [30]. Its use for cooling tower efficiency studies has demonstrated its high efficiency in estimating the heat transfer rate compared to the $\varepsilon$-NTU and Merkel methods. However, its use for industrial cooling tower parametric studies is sparse in the literature. The quest to improve the present technology in the plant also forms the rationale behind this study, thus providing motivation for an improvement in the transfer fluid used in the system. With the peculiarities associated with steel rolling plants in terms of their heat load, this study therefore seeks to fill this gap, thus performing a parametric study on the cooling tower of a steel rolling mill using numerical simulation approach. In this study, the effects of varying cooling tower parameters were investigated using Poppe's method. This study also (i) computes a nodal analysis of significant thermodynamic properties in the system (ii) establishes the significance of the results obtained relative to the case study and makes further conclusion and prospects for further research in the domain.

\section{MATHEMATICAL MODELLING Brief Description of The Steel Plant}

Ajaokuta steel plant is one of the first-generation steel rolling mills in Nigeria aimed at producing long steel products expected to be used in civil engineering and construction industries. The plant, located in Kogi State, the central region of Nigeria, is built on 24,000 hectares of land. The plant operates on Blast Furnace (BF) and Basic Oxygen Furnace (BOF) technologies designed to function at high pressure. By design, the plant was built to integrate iron and steel complex based on the traditional blast furnace for iron production and basic oxygen furnace for steel making [31]. Its expected yearly output of molten iron is estimated to about 1.3 million tons with a provision for increased capacity further to 5.2 million tonnes per annum [32].

\section{Model description}

Structural variations based on functional performance exist in cooling towers. These structural variations affect the analysis and performance of a cooling tower. The rectangular forced convection cooling tower of the steel rolling mill was chosen for this analysis. The cooling tower is divided into four fills. Thermodynamic conditions of first and last fills were known with certainty and taken as initial conditions of the system. The Runge-Kutta fourth order iterative numerical method was used to solve the set of ordinary differential equations. The numerical simulation codes were written and compiled using the SCILAB programming language. Certain parametric performance measures were calculated and their variations with temperature across the fill analysed.

Several approaches to cooling tower parametric study exist in the literature. These include the Merkel, e-NTU and the Poppe's method [6,33-36]. However, the Poppe's method was adopted which rigorously addressed the transport phenomena in the tower packing [11,37]. One of the advantages of the Poppe's method is its efficiency in 
predicting heat transfer rate [26,38] as it is a more rigorous approach of the Merkel and e-NTU method [39]. Even though the Poppe's method does not have most of the simplifying assumptions associated with the Merkel method, it does not consider the liquid film heat transfer resistance [40]. The Poppe's approach permits a supersaturation of the moist air during the heat and mass transfer process. Evaporation rate was evaluated, the heat and mass transfer resistances were taken into account through the estimation of the Lewis factor, the outlet air conditions were calculated, and the NTU was obtained by solving the relevant set of differential equations. Important optimization variables for this model include: water to air mass ratio, water mass flow rate, water inlet and outlet temperatures, operational temperature approach, height and area of the tower packing, total pressure drop of airflow, water consumption, outlet air conditions, and NTU.

\section{Model assumptions}

In this study, certain assumptions were made regarding the system, fluid, and the model. These assumptions are as follows;

i. Steady operating conditions exist and thus mass flow rate of dry air remains constant during the entire process.

ii. Counter flow exists between air and water.

iii. A constant water flow rate is assumed.

iv. Enthalpy of unsaturated air (dry air + water (gas)) $=$ enthalpy of saturated air at normal wet bulb temperature.

v. The laminar air film is assumed not saturated but having the same temperature as the body of water.

vi. Dry air and water vapor are ideal gases.

vii. Water surface resistance to heat and mass transfer is negligible. (The air film is the governing mechanism).

viii. The kinetic and potential energy changes are negligible.

\section{Model equations}

The schematic diagram in Figure 2 is the material flow in the cross flow mechanical draft wet cooling tower. Figure 3 shows the pictorial view of the cooling tower arrangement in the steel rolling mill. Warm water sprayed at the top of the tower mixes with ambient air flowing in a cross-flow direction. Evaporation of water occurs due to partial pressure difference between the water and air. During this process, the air acquires moisture by the virtue of the latent heat of water released into it. The water is cooled in the process and the air is cooled or heated based on the inlet water temperature. The resulting cold water enters the heat system, where it is heated up again and the cycle continues. From the law of energy and mass balance, the heat loss by the hot water from the heat engine is gained by the cold water and cold air. The amount of water circulating the heat engine decreases over time due to evaporation. As a result of this, the make-up water compensates for this loss as shown in Figure 2.

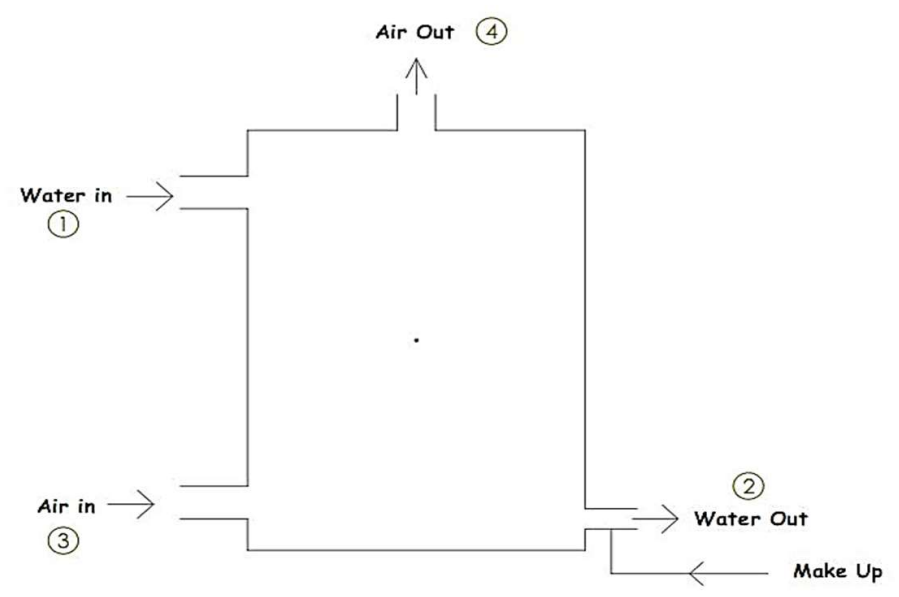

Figure 2. A schematic representation of the cross-flow mechanical draft wet cooling tower 
Journal of Thermal Engineering, Technical Note, Vol. 7, No. 4, pp. 904-917, May, 2021

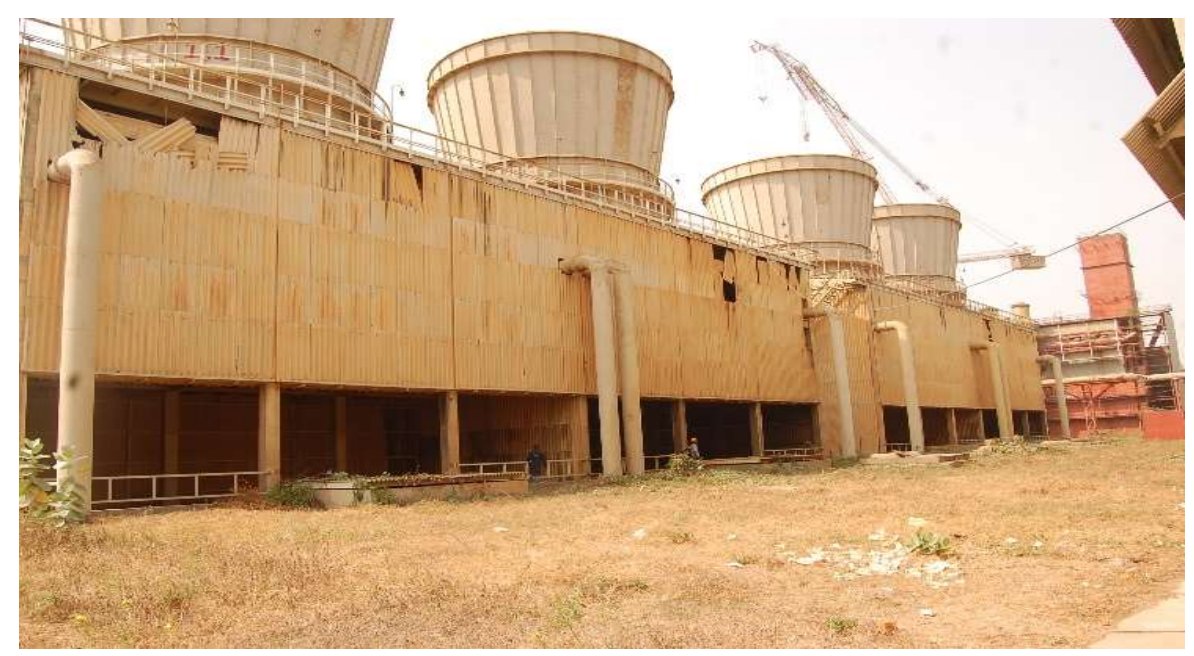

Figure 3. A pictorial view of the arrangement of cooling towers in Ajaokuta Steel Rolling Mill

For unsaturated air, the ordinary differential equation for determining the moisture content $\omega$, enthalpy of the air-vapour mixture $i_{m a}$, and Merkel number $M_{e f}$,for any value of the cooling water temperature $T_{w}$, in the cooling tower are given by [41] as:

$$
\begin{gathered}
\frac{d w}{d T_{w}}=\frac{C_{p w}\left(w_{s w}-w\right)\left(m_{w} / m_{a}\right)}{X} \\
\frac{d i_{m a}}{d T_{w}}=C_{p a}\left(m_{v} / m_{a}\right)\left[1+\left(w_{s w}-w\right) C_{p w} T_{w} / X\right] \\
\frac{d M_{e f}}{d T_{w}}=C_{p w}
\end{gathered}
$$

Parameter $X$ can be calculated using equation (4)

$$
X=i_{\text {masw }}-i_{m a}+\left(L_{e f}-1\right)\left[i_{m a s w}-i_{m a}-\left(w_{s w}-w\right) i_{v}\right]-\left(w_{s w}-w\right) C_{p w} T_{w}
$$

where

$$
\begin{gathered}
i_{\text {masw }}=c_{p a} T_{w}+\omega_{s w}\left(i_{\text {fgwo }}+c_{p v} T_{w}\right) \\
i_{m a}=c_{p a} T_{a}+\omega\left(i_{f g w o}+c_{p v} T_{a}\right)
\end{gathered}
$$

were calculated. By definition, Merkel and Lewis numbers are given as (7) and (8);

$$
\begin{gathered}
M_{e f}=\frac{h_{d} a_{f l} A_{f l} L_{f l}}{m_{w}} \\
L_{e f}=\frac{h}{h_{d} C_{p a}}
\end{gathered}
$$


The mass flow rate of the water in the fill is given by equation (9)

$$
\mathfrak{r}_{w a}=\frac{m_{w}}{m_{a}}=\frac{m_{w i}}{m_{a}}\left[1-\frac{m_{a}}{m_{w i}}\left(w_{o}-w\right)\right]
$$

which can be written as

$$
y_{4}=m_{\text {win }} \times\left(1-\left(m_{a} / m_{\text {win }}\right) \times\left(w_{\text {out }}-y_{1}\right)\right)
$$

Where $w_{\text {out }}$ is air specific humidity at tower top outlet, while $w_{\text {in }}$ is the vapour flow rate at the air inlet located at the bottom of the tower.

\section{Initial conditions}

For counter flow cooling tower (CFCT), it is traditional to choose the bottom of the tower as the initial point. Thus, the value of $w, i_{m a}$ and $M_{e f}$ or (NTU) are known at the bottom of the tower. At the start of the simulation, $\omega=$ $\omega_{1}$, and $i_{m a}=\left(C_{p a 1}+w_{1} C_{p v 1}\right) T_{a 1}$. The specific enthalpy of the inlet air water vapour mixture. $M_{e f}=0$ at the bottom of the tower.

For easy computing, variables were indexed at each fill $i(i=0,1,2,3)$. Following the procedure of Kloppers and Kroger [41], the temperature of the air-vapour mixture is determined once the specific enthalpy is known. It is given by equation (11).

$$
T=\frac{i_{m a}-w i_{f g w o}}{C_{p a}+w C_{p v}}+273.15
$$

where the latent heat of evaporation of water $i_{f g w o}$ is evaluated from equation (12)

$$
i_{f g w o}=3.4831814 \times 10^{6}-5.8627703 \times 10^{3} T+12.1395687 T^{2}-1.40290431 \times 10^{2} T^{3}
$$

The specific heat for dry air, $C_{p a}$ is a function of temperature. It is given by equation (13)

$$
C_{p a}=1045.356-0.3161783 T+7.083814 \times 10^{-4} T^{2}-2.705209 \times 10^{-7} T^{3}
$$

The specific heat for liquid water is given by equation (14) [39]

$$
C_{p w}=8.15599 \times 10^{3}-2.80627 \times 10 T_{w}+5.11283 \times 10^{-2} T_{w}{ }^{2}-2.17582 \times 10^{-13} T_{w}{ }^{6}
$$

The saturated vapour pressure for water vapour in air is given by equation (15)

where;

$$
p_{\text {sat }}=10^{z}
$$

$$
\begin{gathered}
z=10.79586 \times(1-t x)+5.02808 \times \log _{10}\left(T_{x}\right)+1.5047 \times 10^{-4} \times\left(1-10^{\left(-8.29692 \times\left(\frac{1}{T}-1\right)\right)}\right) \\
\text { and } T_{x}=\frac{273.16}{T_{a}}
\end{gathered}
$$

The Lewis factor $L_{e f}$ for unsaturated air is calculated using the equation (18)

$$
y_{8}=L_{e f}=0.865^{2} / 3 \frac{(x-1)}{\left(\log _{(x x)}\right)}
$$

where; 


$$
x=\frac{\left(w_{S w}+0.622\right)}{w+0.622}
$$

The specific humidity $w$ for air temperature at $T_{a}$ is given by equation (20)

$$
w=0.622 \times{ }^{p} /\left(p-p_{s}\right)
$$

where $p$ is the ambient pressure and $p_{s}$ is the partial pressure of the vapour. If the air is saturated, then $p_{s}=p_{s a t}$ and is calculated using equation (15).

Similarly, the vapour flow rate at any position, $y_{5}$, is given by equation (21)

$$
y_{5}=m_{\text {win }}-y_{4}
$$

The mass transfer coefficient, $y_{6}=h_{d}$ is given by equation (22)

$$
y_{6}=h_{d}=M_{e f} m_{w} a_{f l} A_{f l r} L_{f l}
$$

where the Merkel number, $M_{e f}$ is given by the equation (7) and $a_{f l}$ is the wetted area per unit volume of the fill (here set at unity) $[42,43]$ and $A_{f l r}$ is the cross-sectional area of the tower. The mass transfer coefficient was determined by a SCILAB script.

$$
I=\left(X_{w, H(j+1)}-X_{w, H(j)}\right)+\left(X_{a i r, H(j)}+X_{a i r, H(j+1)}\right)
$$

A measure of the quality of energy is defined as exergy, which is the work potential of energy in a given environment. Assuming that air-water thermodynamics properties are known at discrete points along the tower height, the exergy destruction for each incremental tower height $\mathrm{d} H$ is calculated using equation (23).

Table 1. Model initial conditions

\begin{tabular}{lll}
\hline Variable & Unit & Plant data \\
\hline Cooling tower height $\left(\boldsymbol{L}_{\boldsymbol{f} \boldsymbol{l}}\right)$ & $\mathrm{m}$ & 10.0 \\
Cooling tower area $(\boldsymbol{H})$ & $\mathrm{m}^{2}$ & 64.0 \\
Dry air mass flow rate $\left(\boldsymbol{m}_{\boldsymbol{a}}\right)$ & $\mathrm{kg} / \mathrm{s}$ & 750000 \\
Inlet water mass flow rate $\left(\boldsymbol{m}_{\boldsymbol{w} 3}\right)$ & $\mathrm{kg} / \mathrm{s}$ & 15527.728 \\
Atmospheric pressure $\left(\boldsymbol{p}_{\boldsymbol{a}}\right)$ & $\mathrm{N} / \mathrm{m}^{2}$ & 101712.27 \\
Relative humidity $(\boldsymbol{r h})$ & $\%$ & 51.0 \\
Air inlet temperature $\left(\boldsymbol{t}_{\boldsymbol{a} \mathbf{1}}\right)$ & ${ }^{\circ} \mathrm{C}$ & 36.7 \\
Hot water inlet temperature $\left(\boldsymbol{t}_{\boldsymbol{w} \mathbf{3}}\right)$ & ${ }^{\circ} \mathrm{C}$ & 40.0 \\
Water outlet temperature $\left(\boldsymbol{t}_{\boldsymbol{w} \mathbf{4}}\right)$ & ${ }^{\circ} \mathrm{C}$ & 32.0 \\
\hline
\end{tabular}

Table 1 represent the operating conditions and the characteristics of working fluids through the system used as initial conditions. All the equations modelling the system were solved numerically using the computational flow chart shown in Figure 4. This was implemented using the SCILAB scripts described in ref [44]. 


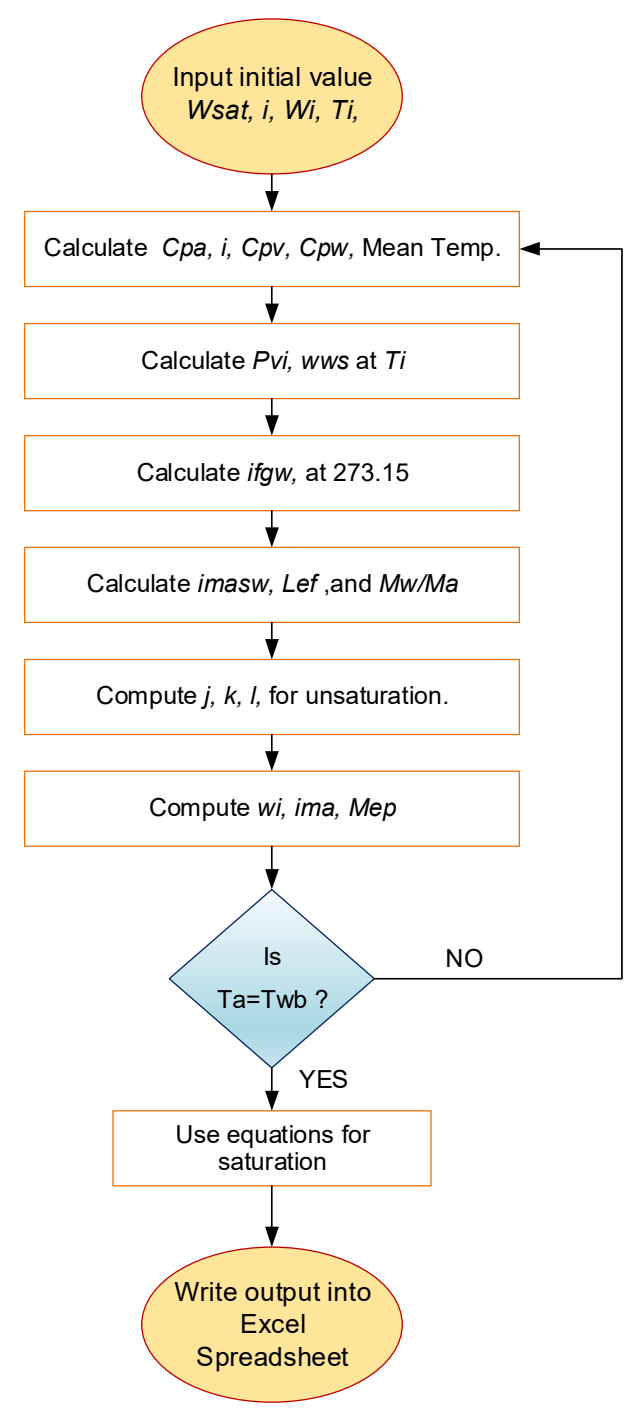

Figure 4. Flow chart of solution procedure

\section{RESULTS AND DISCUSSIONS}

The comparative results are the outlet conditions of the working fluid. Also, the effect of variation in wet bulb temperature of inlet air on various thermodynamic parameters was studied. Thus, this model can be used for predicting the conditions of water and air in cooling towers. Thermodynamic properties vary across the compartments of the tower and invariably across the fills. Many results of the program could be of interest. Since water temperature is used as the independent variable, all other parameters could be tabulated and plotted as a function of the water temperature. For the tower considered, the computed results for water temperature, air moisture content, specific enthalpy and Merkel number at each node beginning from the bottom of the tower is shown in Table 2. The air moisture content increased with the increase in the water temperature throughout the first half of the nodal result. However, a stationary value was obtained in the second half of the nodal result as presented in Table 2. Similar occurrence existed for the Merkel number. This value increases throughout the first half of the nodal result but decreased in the second half of the run. The specific enthalpy on the other hand increases down the nodal results across the cooling tower system. 
Table 2. Cooling tower nodal result

\begin{tabular}{ccccc}
\hline Node & $\boldsymbol{T}_{\boldsymbol{w}}(\boldsymbol{K})$ & $\boldsymbol{w}$ & $\boldsymbol{i}_{\boldsymbol{m} \boldsymbol{a}}(\boldsymbol{J} / \boldsymbol{K g})$ & $\boldsymbol{M e l}$ \\
\hline 1 & 305.15 & 0.0197013 & 87422.10 & 0 \\
2 & 306.48 & 0.0197046 & 87429.42 & 0.4827 \\
3 & 307.82 & 0.0197075 & 87436.26 & 0.8285 \\
4 & 309.15 & 0.0197101 & 87442.84 & 1.0948 \\
5 & 310.48 & 0.0197105 & 87446.58 & 1.1344 \\
6 & 311.82 & 0.0197105 & 87449.78 & 1.1344 \\
7 & 313.15 & 0.0197105 & 87452.96 & 1.1344 \\
8 & 313.15 & 0.0197105 & 87452.96 & 1.1344 \\
\hline
\end{tabular}

Important thermodynamic relationship which varies across the system as heat is rejected from the system were considered. The parametric study of the tower involved perturbations in selected input parameters and determining its effect on the tower performance.

\section{Effect of Increasing Water Temperature on Air Moisture Content}

The variation of moisture content with water temperature from the bottom of the tower is shown in Figure 5. Air moisture content increases with increasing water temperature. This accounts for the addition of make-up water for the evaporative loss in the process. Despite the efficiency of wet-cooling towers, they are known to consume a significant quantities of water, which becomes a problem if the plant is situated in areas with water scarcity [4]. This challenge has lately necessitated recent studies on dry-cooling technologies [45-47], which have recorded laudable water savings most especially in the arid regions.

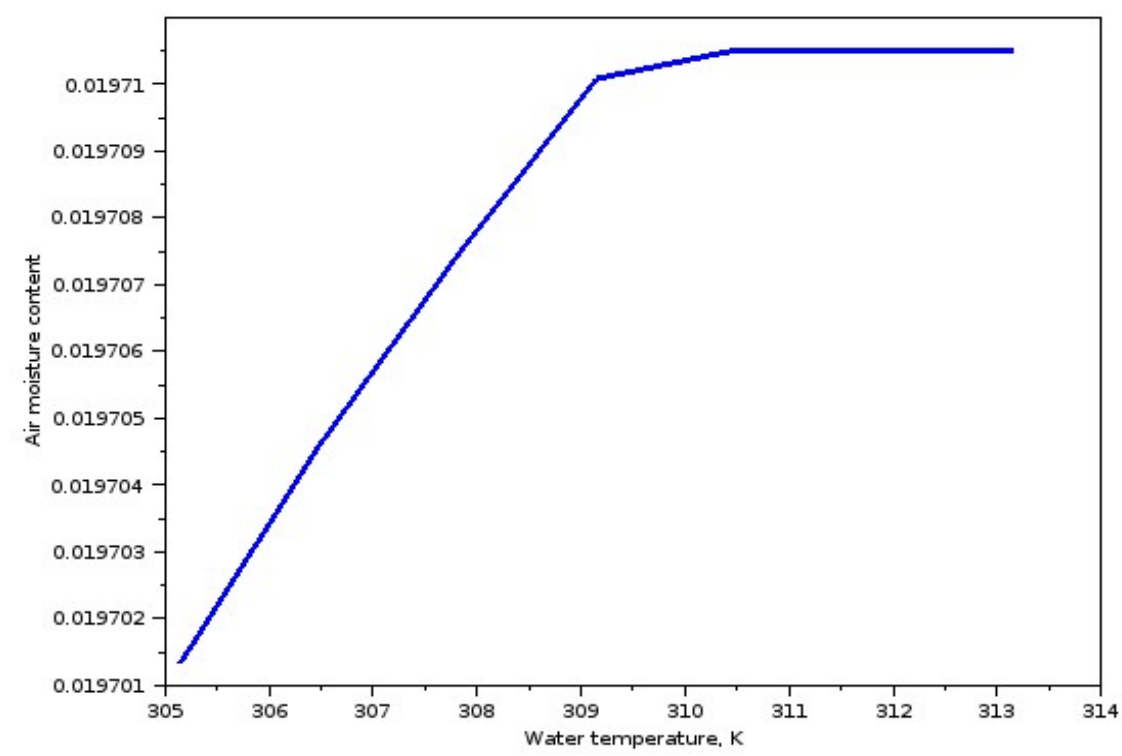

Figure 5. Air moisture content variation with water temperature

\section{Effect of Increasing Water Temperature on the Merkel Number}

The Merkel number, also known as the transfer characteristics, constitute one of the significant parameters that determines the thermal performance of a wet-cooling tower [48]. This parameter depends on the air and water mass flow rates [49]. The variation of Merkel number with water temperature from the bottom of the tower is shown in Figure 6. In this study, it was observed that the Merkel number increases with increasing water temperature. However, at $310^{\circ} \mathrm{C}$ the curve tends to stationarity towards the top of the cooling tower. At this point there exists no 
change in transfer characteristics/coefficient of the system. This correlated with Table 2 appears halfway of the runs. As compared to the study by Zhou et al. [50] the use of forced ventilation, rather than the natural ventilation used in the plant considered in this study, improves the Merkel number and hence the cooling efficiency of the system.

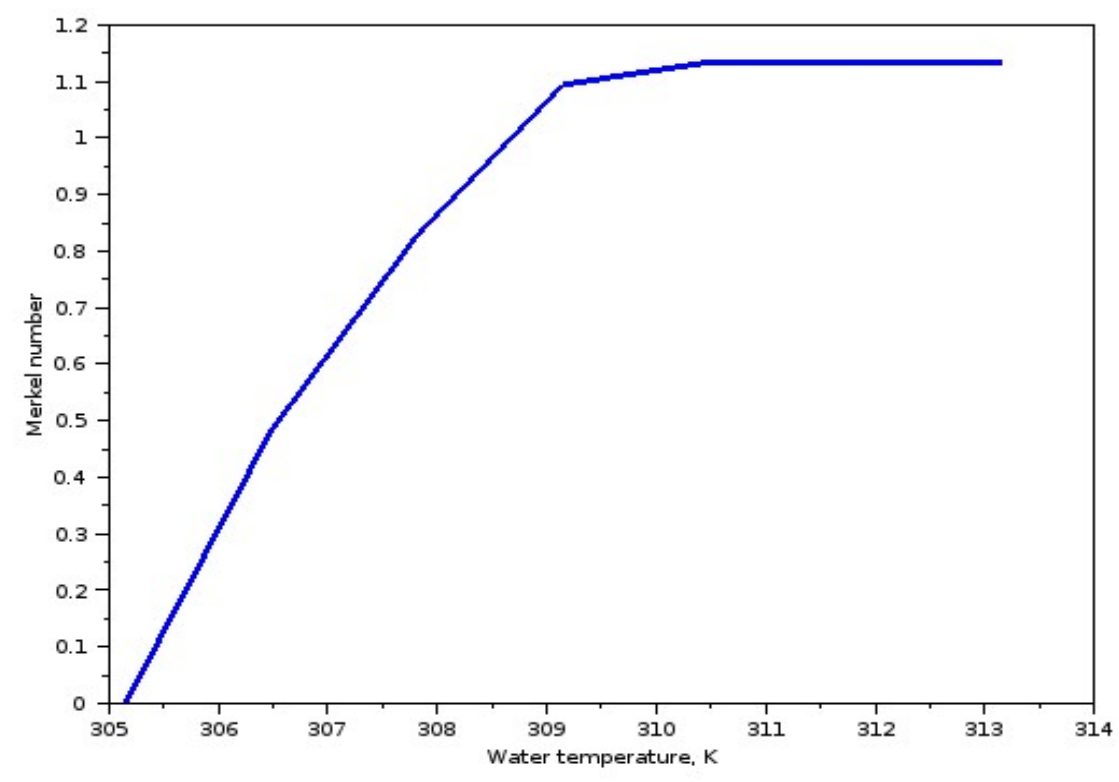

Figure 6. Variation of Merkel Number with water temperature

\section{Effect of Increasing Water Temperature on the Specific Enthalpy}

The top of the tower is associated with high temperature as hot water flows downwards. However, the specific enthalpy of the air vapour mixture increases significantly from the bottom of the tower with a near-linear relationship to the top as shown in Figure 7. This shows that sensible heat is lost as water flows from top to the bottom of the tower, which leads to considerable evaporative cooling. Hence, a makeup water is necessary to compensate for the lost water in the system.

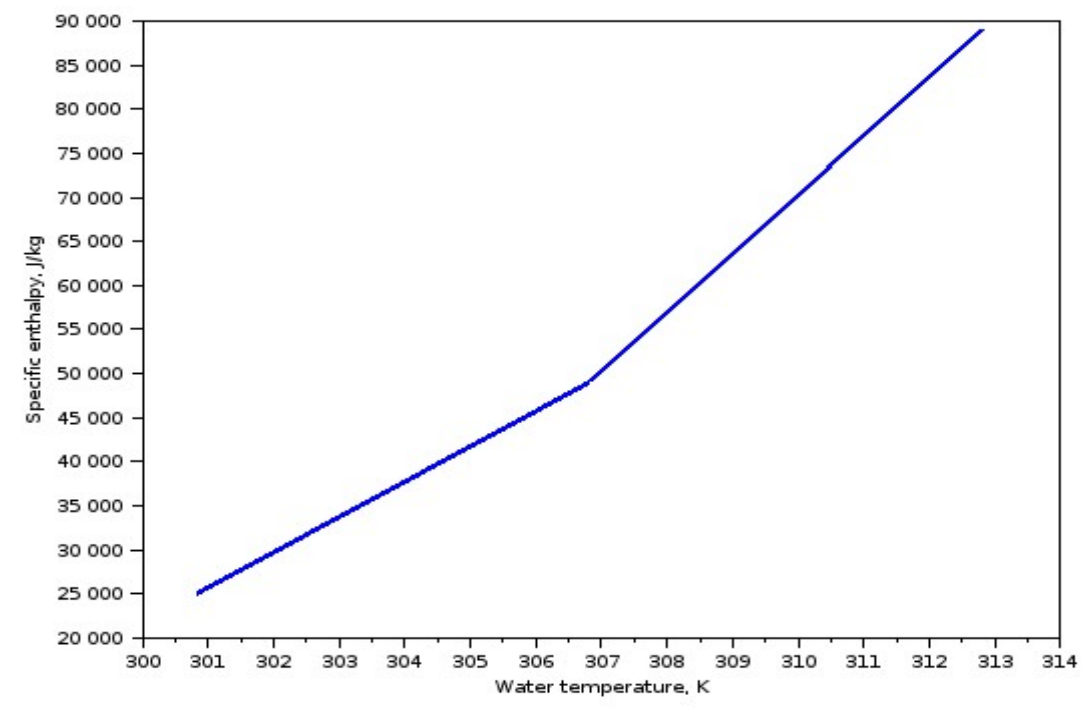

Figure 7. The variation of specific enthalpy of the air vapour mixture with water temperature from the bottom of the tower 
Similar study performed by [37] on a campus vapour compression refrigeration system obtained a positive correlation between the water temperature and other thermodynamic variables like the specific gravity, though the temperature difference between the tower head is significantly different. Perturbations in the water temperature has a ripple effect on the cooling tower parameters from top to the bottom.

Recent advances in the field of nanofluids have established remarkable improvement in the capabilities of conventional fluids for convective cooling [51]. Nanosized metallic and non-metallic materials have lately been used to enhance heat transfer in convective fluids [2,51], thus ensuring high heat transfer rate. These nanocomposites are of high functionality, however, high frictional effect and increased pump power requirement has been one of their major drawbacks. Industrial cooling towers are known for high heat removal and thus, improving the heat transfer rate in the process proffers faster cooling. There are several nanoparticles known for high heat removal rate in cooling systems. Some of these include the $\mathrm{Al}_{2} \mathrm{O}_{3}, \mathrm{TiO}_{2}, \mathrm{CuO}, \mathrm{SiO}_{2}$, carbon nanotubes (CNT), $\mathrm{ZnO}$, and so on [52]. Their respective concentrations under varying applications have been investigated in many studies. From these studies, it is established that the nanoparticle concentration and frictional effect are directly related [53]. Enhancing the heat transfer rate of in heat systems using nanoparticles have been implemented mostly in automobiles and allied systems, however, studies on their applications in industrial cooling towers is still at sparse in the literature. Addition of nanocomposites at tested concentration in the convective cooling fluid of the cooling tower has a high prospect of increasing the heat transfer rate of the system.

\section{CONCLUSIONS AND PROSPECTS}

In this study, we investigated the downstream variation in the water temperature on some selected thermodynamic properties of a typical cooling tower used in a steel rolling mill using numerical method. For a rectangular cooling tower load, the model successfully predicts air and water outlet temperatures. For parametric analysis of a cooling tower, the model successfully predicted the behaviour of all the parameters involved in the experiment. Air moisture temperature increases as the water temperature increases. The Merkel number across the system increases with increasing water temperature. The result obtained from the study confirmed that in the literature [37]. Increase in water vapour temperature towards the tower outlet and increase in enthalpy across the fill necessitates an increase in the make-up water entering the system. Even though all other variables increased at and reached a stationary point at half the total nodal points considered in the analysis, the specific enthalpy of the system increases throughout the system. The thermal efficiency could be improved upon by the introduction of a force draft system. With the present steps in the plant towards improving the existing technology, the nanoparticles with high thermal conductivity but less frictional effect is recommended for the present or new technology in the mill. However, economic feasibility of this inclusion in large scale industrial cooling towers is highly essential. Also, in contrast with the use of numerical models, the use of artificial intelligence techniques can be explored in further studies towards monitoring the cooling tower parameters.

\section{NOMENCLATURE}

$\boldsymbol{a}_{f l} \quad$ The wetted area per unit volume of the fill, $\mathrm{m}^{2}$

$\boldsymbol{A}_{\boldsymbol{f l}} \quad$ Cross sectional area of the tower, $\mathrm{m}^{2}$

$\boldsymbol{C}_{\boldsymbol{p a}} \quad$ Specific heat for dry air, $\mathrm{kJ} / \mathrm{kgK}$

$\boldsymbol{C}_{\boldsymbol{p} w} \quad$ Specific heat for liquid water, $\mathrm{kJ} / \mathrm{kgK}$

$\boldsymbol{C}_{\boldsymbol{p a}} \quad$ The specific heat for dry air, $\mathrm{kJ} / \mathrm{kgK}$

$\boldsymbol{C}_{\boldsymbol{p} v} \quad$ Specific enthalpy for water vapour at constant pressure, $\mathrm{kJ} / \mathrm{kgK}$

$\boldsymbol{h} \quad$ Enthalpy of the bulk air, $\mathrm{kJ} / \mathrm{kg}$

$\boldsymbol{h}_{\boldsymbol{d}} \quad$ Mass transfer coefficient of air, $\mathrm{kW} / \mathrm{m}^{2} \mathrm{~K}$

$\boldsymbol{i}_{\text {fgwo }} \quad$ Latent heat of evaporation of water, $\mathrm{kJ} / \mathrm{kgK}$

$\boldsymbol{i}_{\boldsymbol{m} \boldsymbol{a}} \quad$ Enthalpy of the air-vapour mixture, $\mathrm{kJ} / \mathrm{kg}$

$\boldsymbol{i}_{\text {masw }} \quad$ Enthalpy od saturated air at $T_{w}, \mathrm{~kJ} / \mathrm{kg}$

$\boldsymbol{i}_{v} \quad$ Enthalpy of water vapour at $T_{w}, \mathrm{~kJ} / \mathrm{kg}$ 


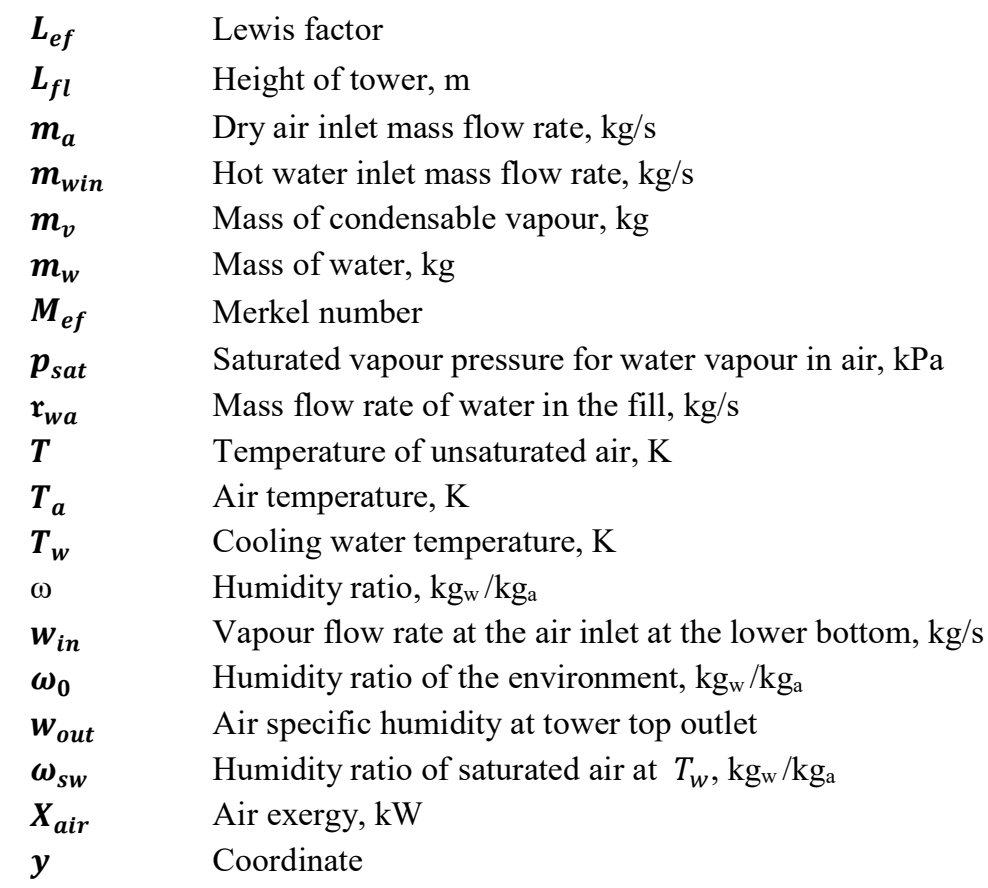

\section{REFERENCES}

[1] Guo Y, Wang F, Jia M, Zhang S. Parallel hybrid model for mechanical draft counter flow wet-cooling tower. Appl Therm Eng 2017;125:1379-88. doi:10.1016/j.applthermaleng.2017.07.138.

[2] Ali HM, Azhar MD, Saleem M, Saeed QS, Saieed A. Heat transfer enhancement of car radiator using aqua based magnesium oxide nanofluids. Therm Sci 2015;19:2039-48. doi:10.2298/TSCI150526130A.

[3] Ali H, Liaquat H, Maqsood B. Experimental investigation of convective heat transfer augmentation for car radiator using $\mathrm{ZnO}$ - water nano fluids. Energy 2015;84:317-24. doi:10.1016/j.energy.2015.02.103.

[4] Li X, Gurgenci H, Guan Z, Wang X, Xia L. A review of the crosswind effect on the natural draft cooling towers. Appl Therm Eng 2019;150:250-70. doi:10.1016/j.applthermaleng.2018.12.147.

[5] Rai P, Khan AI. Performance ANalysis of Cooling Tower: A Review. Int J Innov Res Sci Eng 2016;2:96-102.

[6] Dhorat A, Al-Obaidi MA, Mujtaba IM. Dynamic modelling and operational optimisation of natural draft cooling towers. Therm Sci Eng Prog 2019;9:30-43. doi:10.1016/j.tsep.2018.10.013.

[7] Arunkumar S, Sivakumar, D. B. Senthilkumar T. Fabrication and Performance Analysis of Cooling Tower. Int J Eng Sci Comput 2016:5359-62.

[8] Kumar D, Zehra T, Junejo A, Bhanbhro SA, Basit M. 4E (Energy, Exergy, Economic and Environmental) Analysis of the Novel Design of Wet Cooling Tower. J Therm Eng 2020;6:252-67. doi:10.18186/thermal.710981.

[9] Merkel F. Evporative cooling. Z Verein Deutsch Ingen 1925;70:123-8.

[10] Miao W, Jin W, Jiajin W, Cheng SHI. Contrastive Analysis of Cooling Performance between a High-level Water Collecting Cooling Tower and a Typical Cooling Tower. J Therm Sci 2018;27:39-47.

[11] Kl-oppers JC, Kroger DG. Cooling tower performance evaluation: Merkel, Poppe, and eNTU methods of analysis. J Eng Gas Turb Power 2005; 127:1-7.

[12] Khan JR, Zubair SM. Performance characteristics of counter flow wet cooling towers. Energy Convers Manag 2002;44:2073-91.

[13] Prasad M. Economic upgradation and optimal use of multi-cell cross flow evaporative water cooling tower through modular performance appraisal. Appl Therm Eng 2003;24:579-93.

[14] Hajidavalloo E, Shakeri R, Mehrabian MA. Thermal performance of cross flow cooling towers in variable wet bulb temperature. Energy Convers Manag 2010;51:1298-303.

[15] SPX. Cooling Tower Performance: Basic Theory and Practice. Overland Park: SPX Cooling Technologies Inc..; 2013.

[16] SPX. Cooling Tower Fundamentals. U.S.A.: SPX Cooling Technologies Inc..; 2009

[17] Olatunji O, Akinlabi S, Ajayi O, Madushele N. A survey of Artificial Neural Network-based Prediction Models 
for Thermal Properties of Biomass. Procedia Manuf 2019;33:184-91. doi:10.1016/j.promfg.2019.04.103.

[18] Adedeji PA, Akinlabi S, Ajayi O, Madushele N. Non-linear autoregressive neural network (NARNET) with SSA filtering for a university enegy consumption forecast. 16th Glob. Conf. Sustain. Manuf. Sustain. Manuf. Glob. Circ. Econ., 2019, p. 176-83. doi:.1037//0033-2909.I26.1.78.

[19] Adedeji P, Madushele N, Akinlabi S. Adaptive Neuro-fuzzy Inference System ( ANFIS ) for a multi-campus institution energy consumption forecast in South Africa 2018:950-8.

[20] Guo Q, Qi X, Wei Z, Yin Q, Sun P, Guo P, et al. Modeling and characteristic analysis of fouling in a wet cooling tower based on wavelet neural networks. Appl Therm Eng 2019;152:907-16. doi:10.1016/j.applthermaleng.2019.02.041.

[21] Hosoz M. Performance prediction of a cooling tower using artificial neural network. Energy Convers Manag 2007;48:1349-59. doi:10.1016/j.enconman.2006.06.024.

[22] Homod RZ. Review on the HVAC System Modeling Types and the Shortcomings of Their Application. J Energy 2013:1-10.

[23] Rashidi MM, Bég OA, Parsa AB, Nazari F. Analysis and optimization of a transcritical power cycle with regenerator using artificial neural networks and genetic algorithms. Proc Inst Mech Eng Part A J Power Energy 2011;225:701-17. doi:10.1177/0957650911407700.

[24] Rashidi MM, Ali M, Freidoonimehr N, Nazari F. Parametric analysis and optimization of entropy generation in unsteady MHD flow over a stretching rotating disk using artificial neural network and particle swarm optimization algorithm. Energy 2013;55:497-510. doi:10.1016/j.energy.2013.01.036.

[25] Rashidi MM, Galanis N, Nazari F, Parsa AB, Shamekhi L. Parametric analysis and optimization of regenerative Clausius and organic Rankine cycles with two feedwater heaters using artificial bees colony and artificial neural network Clausius Rankine cycle. Energy 2011;36:5728-40. doi:10.1016/j.energy.2011.06.036.

[26] Zhang Y, Zhang H, Wang Y, You S, Zheng W. Optimal configuration and operating condition of counter flow cooling towers using particle swarm optimization algorithm. Appl Therm Eng 2019;151:318-27. doi:10.1016/j.applthermaleng.2019.01.097.

[27] Gao M, Sun F, Zhou S, Shi Y, Zhao Y, Wang N. Performance prediction of wet cooling tower using artificial neural network under cross-wind conditions. Int J Therm Sci 2009;48:583-9. doi:10.1016/j.ijthermalsci.2008.03.012.

[28] Qi X, Liu Z, Li D. Numerical simulation of shower cooling tower based on artificial neural network. Energy Convers Manag 2008;49:724-32. doi:10.1016/j.enconman.2007.07.032.

[29] Kalatuzov VA. A procedure for constructing the normative characteristics of chimney-type evaporative cooling towers from the results of field measurements. Therm Eng 2007;54:901-5. doi:10.1134/s0040601507110092.

[30] Nasrabadi M, Finn DP. Mathematical modeling of a low temperature low approach direct cooling tower for the provision of high temperature chilled water for conditioning of building spaces. Appl Therm Eng 2014;64:273-82.

[31] Adetula Y, Bamidele EA. Timely Completion of Nigerian Iron and Steel Projects: the imperative of technical manpower development. 29th Annu. Conf. AGM Niger. Metall. Soc. Ajaokuta Steel Co., 2013.

[32] Ajaokuta Steel Company Limited. Company Overview : Ajaokuta Steel Company. Ajaokuta Steel Co 2019. http://www.ajaokutasteel.com/site/pagef.php?cnt=Company Overview (accessed May 11, 2019).

[33] Kroger DG. Air-Cooled Heat Exchangers and Cooling Towers. Tulsa, Oklahoma: PennWell Corp..; 2004.

[34] Kashani MMH, Dobrego K V. Heat and mass transfer in natural draft cooling towers. J Eng Phys Thermophys 2013;86:1072-82. doi:10.1007/s10891-013-0930-z.

[35] Chen X, Sun F, Chen Y, Gao M. Novel method for improving the cooling performance of natural draft wet cooling towers. Appl Therm Eng 2019;147:562-70. doi:10.1016/j.applthermaleng.2018.10.076.

[36] Akkaya A V. Performance analyzing of an organic rankine cycle under different ambient conditions. J Therm Eng 2017;3:1498-504. doi:10.18186/journal-of-thermal-engineering.338897.

[37] Naik BK, Muthukumar P. A novel approach for performance assessment of mechanical draft wet cooling towers. Appl Therm Eng 2017;121:14-26. doi:10.1016/j.applthermaleng.2017.04.042.

[38] Naik BK, Choudhary V, Muthukumar P, Somayaji C. Performance Assessment of a Counter Flow Cooling Tower - Unique Approach. Energy Procedia 2017;109:243-52. doi:10.1016/j.egypro.2017.03.056.

[39] Kloppers JC, Kroger DG. Cooling Tower Performance Evaluation : Merkel, Poppe, and e -NTU Methods of Analysis. J Eng Gas Turbines Power 2005;127:1-7. doi:10.1115/1.1787504.

[40] Ren C. An Analytical Approach to the Heat and Mass Transfer Processes in Counterflow Cooling. Trans ASME 2006;128:1-7. doi:10.1115/1.2352780. 
[41] Kloppers JC, Kroger DG. A Critical Investigation into the Heat and Mass Transfer Analysis of Counterflow Wet-Cooling Towers. Int J Heat Mass Transf 2005:765-77.

[42] ASHRAE. Fundamentals: ASHRAE Handbook. Atlanta: American Society of Heating, Refrigeration and AirConditioning Engineers; 2009.

[43] Nicklas S, Strehlow G, Duda SW, Simmonds P. 2016 HVAC Systems and Equipment. ASHRAE; 2016.

[44] Bamimore OT. Paramteric Effects on the Performance of an Industrial Cooling Tower (A Case Study of Ajaokuta Power Plant). 2016.

[45] Zou Z, Guan Z, Gurgenci H, Lu Y. Solar enhanced natural draft dry cooling tower for geothermal power applications. Sol Energy 2012;86:2686-94. doi:10.1016/j.solener.2012.06.003.

[46] Ge W, Fan J, Liu CX, Li W, Chen G, Zhao Y. Critical impact factors on the cooling performance design of natural draft dry cooling tower and relevant optimization strategies. Appl Therm Eng 2019;154:614-27. doi:10.1016/j.applthermaleng.2019.03.008.

[47] Dong P, Li X, Hooman K, Sun Y, Li J, Guan Z, et al. The crosswind effects on the start-up process of natural draft dry cooling towers in dispatchable power plants. Int J Heat Mass Transf 2019;135:950-61. doi:10.1016/j.ijheatmasstransfer.2019.02.039.

[48] Dang Z, Zhang Z, Gao M, He S. Numerical simulation of thermal performance for super large-scale wet cooling tower equipped with an axial fan. Int $J$ Heat Mass Transf 2019;135:220-34. doi:10.1016/j.ijheatmasstransfer.2019.01.111.

[49] Klimanek A. Numerical Modelling of Natural Draft Wet-Cooling Towers. Arch Comput Methods Eng 2013;20:61-109. doi:10.1007/s11831-013-9081-9.

[50] Zhou Y, Gao M, Long G, Zhang Z, Dang Z, He S. Experimental study regarding the e ff ects of forced ventilation on the thermal performance for super-large natural draft wet cooling towers. Appl Therm Eng 2019;155:40-8. doi:10.1016/j.applthermaleng.2019.03.149.

[51] Babar H, Sajid MU, Ali HM. Viscousity of Hybrid Nanofluids: a critical review. J Therm Sci 2019:1-49.

[52] Sajid MU, Ali HM. Recent advances in application of nanofluids in heat transfer devices : A critical review. Renew Sustain Energy Rev 2019;103:556-92. doi:10.1016/j.rser.2018.12.057.

[53] Hussein AM, Bakar RA, Kadirgama K. Case Studies in Thermal Engineering Study of forced convection nanofluid heat transfer in the automotive cooling system. Case Stud Therm Eng 2014;2:50-61. doi:10.1016/j.csite.2013.12.001. 